\title{
Evaluating teat skin condition in response to phenoxyethanol as a post-milking teat disinfectant on lactating dairy cows
}

\begin{abstract}
Alternatives to iodine-based teat dips may decrease risk of iodine residues in milk. The objective of this study was to evaluate how a post-milking teat dip containing phenoxyethanol as the active ingredient and a $5 \%$ emollient (treatment) affected teat skin condition compared to a $1 \%$ iodine solution (control). A 9 week, split-udder, noninferiority study was conducted on 111 lactating Holstein dairy cows at the University of Kentucky Coldstream Research Dairy. The treatment (left side) and control (right side) were applied using a non-return dip cup. Teats were scored once a week, in accordance with National Mastitis Council guidelines, for 9weeks on a 1 (desirable) to 3 (undesirable) scale for teat skin chapping, teat skin dryness, and teat skin color. A 1 (desirable) to 4 (undesirable) scale was used for teat end condition. Data analyses were conducted with SAS Version 9.3 (SAS Institute Inc., Cary, NC). The FREQ procedure generated frequency distributions and the MIXED procedure generated a mixed linear model evaluating the effect of teat, week, and their interaction on teat end condition, teat skin color, teat skin chapping, and teat skin dryness. Teat skin chapping and teat skin color remained at a score of 1 throughout all 9weeks of the study and were not analyzed further. For teat end condition, no significant differences in scores between treatment and control teats were observed. For teat dryness, scores for treatment front teats were significantly greater than control front teats $(1.10 \pm 0.01$ vs. $1.06 \pm 0.01 ; \mathrm{P} \leq 0.001)$. Temporary increases in dryness scores during study weeks 4 , 5,6 , and $9(\mathrm{P} \leq 0.01)$ on the treatment side occurred during expected teat exfoliation. Teat skin condition gradually decreased overtime with statistically different scores during weeks $1,3,4,6(\mathrm{P} \leq 0.01)$, and $7(\mathrm{P} \leq 0.012)$. The scores comparing treatment and control teats are significantly different, but are minimal enough that they do not suggest a biological difference. Results indicate phenoxyethanol may serve as an alternative to iodine-based teat dips, which raise risk of iodine residues in milk
\end{abstract}

Volume 6 Issue 2 - 2017

\author{
Selene K Reeves, Matthew R Borchers, \\ Jeffrey M Bewley \\ Department of Animal and Food Sciences, University of \\ Kentucky, USA
}

Correspondence: Matthew R Borchers, Department of Animal and Food Sciences, University of Kentucky, USA, 413 W.P. Garrigus Building, Lexington, KY 40506, USA, Tel 93744I8339, Email matthew.borchers@uky.edu

Received: July 21, 2017 | Published: December 18, 2017

Keywords: post-dip, teat skin condition, mastitis

\section{Introduction}

Mastitis is a mammary infection caused by the passage of pathogens into the mammary gland. Deteriorations in teat health are shown to be related to this type of infection. ${ }^{1}$ Rough or cracked teats allow mastitis pathogens to colonize the udder. Roughness and cracking of the teat is related to hyperkeratosis, the condition of teat end callosity. Rough or cracked teats allow mastitis pathogens to colonize the udder causing hyperkeratotic teat end lesions that are related to increases in the risk of intramammary infections and mastitis. ${ }^{2,3}$ Causes that contribute to poor teat condition and hyperkeratosis include: harsh weather conditions, milking machine factors, and poor milking management. ${ }^{4}$ In cold and harsh weather environments, teat skin can suffer from deterioration causing teat skin chapping and increased mastitis frequency. ${ }^{5} \mathrm{~A}$ mixture of cold temperatures, weather exposure, and residual milk on teat ends can lead to teat end freezing. ${ }^{6}$ In contrast, hot and humid climates increase infection rate, due to high environmental moisture levels. ${ }^{7}$ Increases in environmental mastitis-causing pathogens may occur during the hot and moist summer months. ${ }^{8}$

Milking management practices can also affect teat health. Poor milking machine maintenance such as uneven pulsation or high vacuum pressure can reduce overall teat health. ${ }^{9}$ Following milking, teat discoloration, overall firmness, and ring thickening near teat ends are all issues associated with improper use of teat cup liners in combination with overmilking. ${ }^{9}$ Failure to regularly sanitize teat cups and replace milking filters, are major setbacks that may lead to poor teat health. ${ }^{10}$ One way to prevent poor teat health and high levels of hyperkeratosis is by using post-milking antiseptic solutions. ${ }^{4}$ The inclusion of an emollient can help reduce roughness of the teat end caused by harsh active chemical ingredients with low $\mathrm{pH}$ values, such as iodine, used in teat disinfectants. ${ }^{4}$ Using these disinfectants along with effective milking management practices could greatly reduce intramammary infection incidence. ${ }^{11}$ The objective of this study was to show that a post-dip, containing the active ingredient phenoxyethanol with $5 \%$ emollient would not have a different effect on teat end condition, teat skin chapping, teat skin dryness, and teat skin color when compared to a commonly used iodine based teat dip. Phenoxyethanol has some mild hazardous properties when used alone causing some concern, however this chemical meets the Safer Choice Criteria by the United States Environmental Protection Agency (EPA) due to its significant functionality in similar products. ${ }^{12}$ Evaluating phenoxyethanol as a post-milking teat dip is important in an effort to find alternatives to using iodine as a post-milking teat dip.

\section{Materials and methods}

Lactating Holstein dairy cows $(n=111)$ at the University of 
Kentucky Coldstream Dairy Research Farm were used in a 9week split-udder study. Cows were milked at 0300 and 1530 daily in a two by two bypass parlor using automatic take-offs. New facilities at the University of Kentucky were constructed to house the lactating cow herd. Approximately one week before the beginning of the study, cows were housed in a freestall barn and moved to a new compost bedded pack barn facility. Packs were bedded with kiln-dried sawdust as needed and aerated twice daily using a rototiller. A minimum of $9 \mathrm{~m}^{2}$ compost bedded pack per cow was provided for the entirety of the study. A TMR (total mixed ration) was delivered twice per day and pushed up at regular intervals. Following the first week of treatment application, teat health was assessed for normal reactions to the product in order to determine if the study should continue. The treatment was a post-dip solution containing the active ingredient phenoxyethanol with $5 \%$ emollient. The post-dip is a ready-to-use green, aqueous solution, at a $1 \%$ dilution. The control was the herd's standard $1 \%$ iodine solution applied, during the study, as a pre-dip to all teats before milking for 30seconds, and the right side of the udder after milking. The treatment and control were applied using a nonreturn teat dip cup.

Teat scoring was completed once per week during the afternoon milking after the milking clusters were detached prior to application of the treatment according to National Mastitis Council approved methods. ${ }^{13}$ Teat end condition was scored on a 1 to 4 scale, corresponding to the visibility of a hyperkeratosis ring. A score of 1 indicated no visible ring, 2 indicated moderate visibility, 3 indicated complete visibility, and 4 indicated extreme ring thickness). ${ }^{13}$ Teat condition was scored using three parameters. Teat skin color, teat skin dryness, and teat skin chapping were each scored on a 1 to 3 scale. Color was evaluated by examining any change in color tint or pigment. A score of 1 indicated a teat with normal pink coloring, 2 indicated a hint of blue or red coloring, and a score of 3 indicated complete reddening of teat skin. ${ }^{13}$ Dryness was evaluated using a friction test examining resistance upon touch determined by the scorer. ${ }^{12} \mathrm{~A}$ score of 1 indicated a smooth surface with no frictional resistance involved, 2 indicated slight frictional resistance and slight roughness, and a 3 indicated extreme roughness and a high frictional resistance level. ${ }^{13}$ Teat skin chapping was evaluated by observing cracks on the skin surface. A score of 1 indicated a smooth surface with no visible cracking, 2 indicated minor appearances of skin cracks, and 3 indicated extensive and irritated skin cracking. ${ }^{13}$ Following milking and teat condition scoring, the treatment, was applied to the left teats and the control was applied to the right.

Statistical analyses were conducted using SAS Version 9.3 (SAS Institute Inc., Cary, NC). Frequency distributions were generated using the FREQ procedure of SAS (SAS Institute Inc., Cary, NC). A mixed linear model (MIXED procedure) was used to evaluate the effect of teat, week of study (week 1 through week 9), and the interaction of teat and week on teat end, color, chapping, and dryness scores. Cow teat (left front (LF), right front (RF), left rear (LR), right rear (RR)), and week (week 1 through week 9) served as categorical variables. Teat end condition, teat skin color, teat skin chapping, and teat skin dryness were all treated as dependent variables. Teat and week served as repeated variables and cow served as a repeated subject. A directproduct autoregressive covariate structure was used in all models. Least-squares means were adjusted using Tukey's test. ${ }^{14,15}$

\section{Results and discussion}

Scores remained at a 1 for teat skin color and teat skin chapping for the duration of the study, therefore no further analyses were performed. The teat scored, the week of the study, and the interaction of teat and week of the study were all significant predictors of teat dryness and teat end condition $(P \leq 0.001)$. Individual examination of teat end condition on each teat showed no significant differences between treatment and control as shown in Figure 1. However, when comparing the front teats with the rear teats on either the treatment or the control side of the udder there were significant differences between scores. On the treatment side, the front teat was scored greater than the rear teat (mean $\pm \mathrm{SD} ; 1.89 \pm 0.03$ vs. $1.81 \pm 0.02)$. Similar results occurred on the control side of the udder, with the front teat scoring higher than the rear teat $(1.93 \pm 0.03$ vs. $1.79 \pm 0.02)$. This difference could be attributed to a tendency of front teats to give less milk than rear teats. ${ }^{16}$ As a result, the front teats are at greater risk of being over milked in comparison to the rear teats, causing an increase in teat end scores. ${ }^{17}$ Teat dryness scores in the front teats of the treatment side were significantly greater than control teats $(1.10 \pm 0.01$ vs. $1.06 \pm .01$; $\mathrm{P} \leq 0.001)$. No significant differences were found between treatment and control scores in the rear teats for teat drynessas shown in Figure 2. Overall, the difference in teat end condition and teat skin dryness scores discussed are minimal enough that they may not suggest a biological difference.

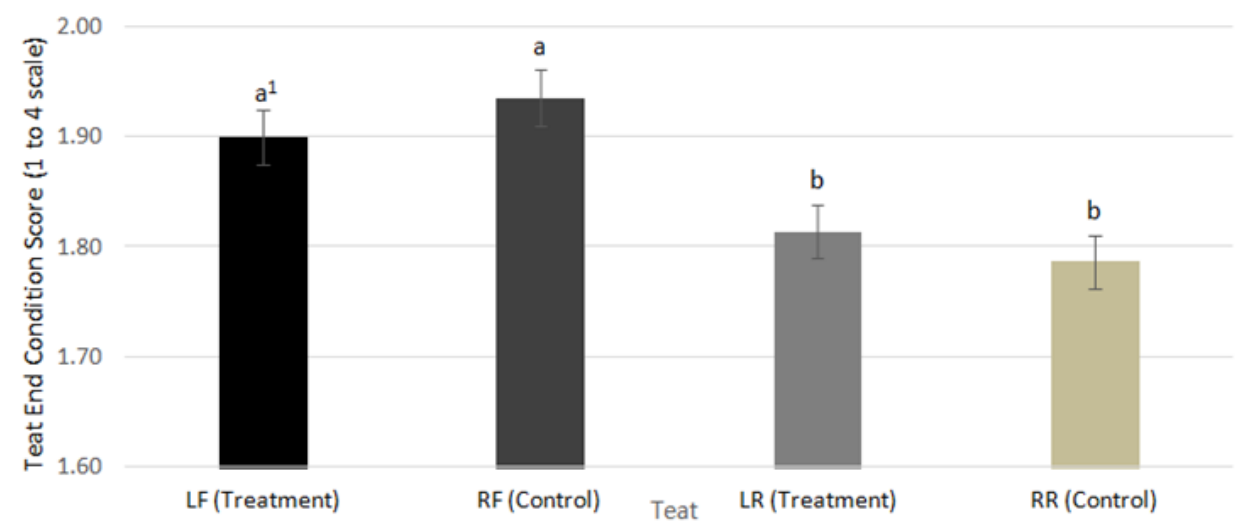

Figure I Frequency distribution of mean teat end condition scores generated by the FREQ procedure of SAS Version 9.3 on the LF, RF, LR, and RR teats throughout all nine weeks of the study comparing the treatment (phenoxyethanol) and the control (I\% iodine).

'Bars differing in letters differ significantly $(P<0.05)$. 


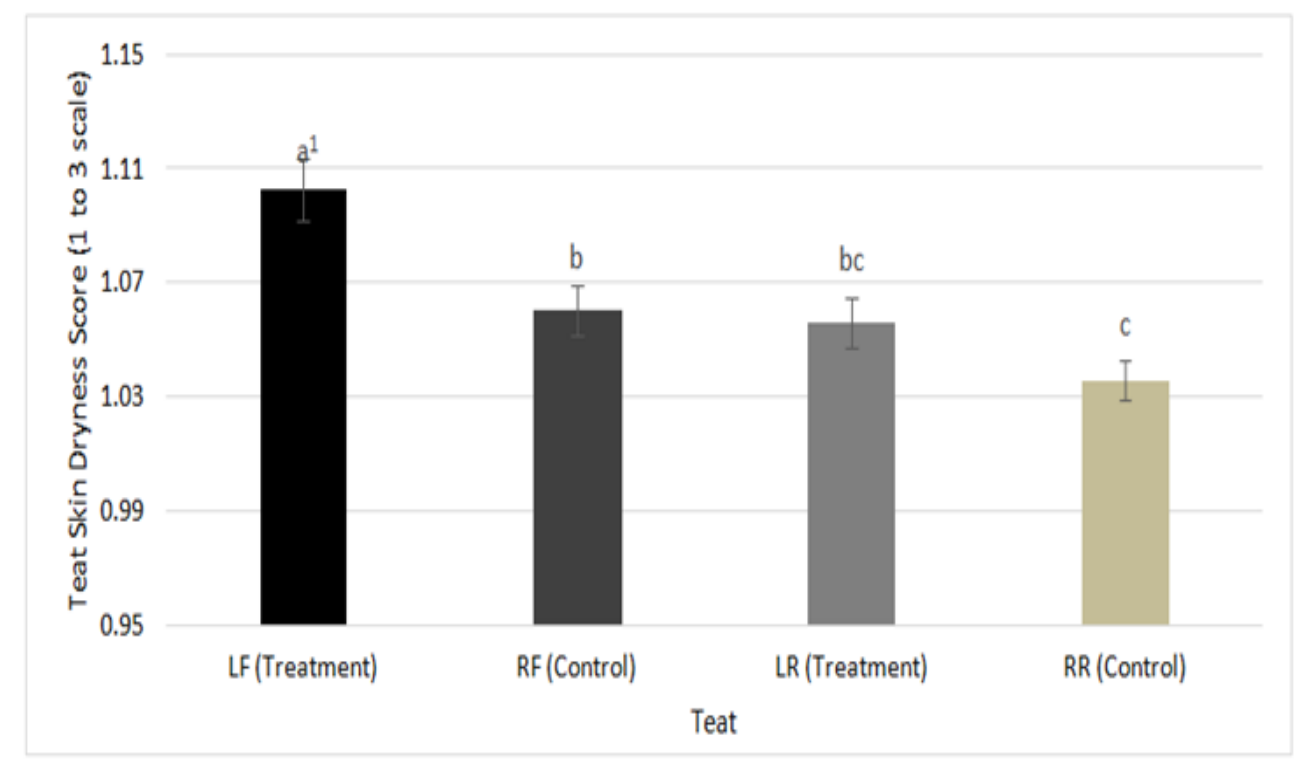

Figure 2 Frequency distribution of mean teat skin dryness scores generated by the FREQ procedure of SASVersion 9.3 on LF, RF, LR, and RR teats throughout all nine weeks of the study comparing the treatment (phenoxyethanol) and the control (I\% iodine).

' Bars differing in letters differ significantly $(P<0.05)$.

Least squares means for both teat dryness and teat end condition by week from a mixed linear model are shown in Figure 3 \& 4, respectively. Overall, teat end condition scores gradually decreased over time. Scores were statistically different among all four teats during week one $(P \leq 0.001)$, three $(P \leq 0.001)$, four $(P=0.002)$, six $(P \leq 0.001)$, and seven $(P=0.012)$. Because teat ends condition scores were already different during the first week of the study this may suggest the difference in scores, overtime, was not directly related to the treatment. In the beginning of this study, cows were moved into a new compost bedded pack barn from a previous free stall barn which may have been a contributor to decreased scores over time. Improved teat conditions in the form of teat end lesions are associated with the use of softer flooring materials. ${ }^{18}$ Teat dryness scores were statistically different among all four teats during weeks four $(P \leq 0.001)$, five $(P \leq 0.001)$, six $(P=0.002)$, and nine $(P=0.002)$. Dryness increased during weeks four through six due to normal signs of exfoliation. Exfoliation is the removal of dead outer skin cells and is usually marked by a temporary increase in dryness scores as shown in a previous study. ${ }^{19}$ Dryness scores returned to normal by the end of the study as shown in Figure 4. A longer study may be needed to determine whether exfoliation on the udder occurs continually with long-term use and whether or not this would further affect teat skin condition.

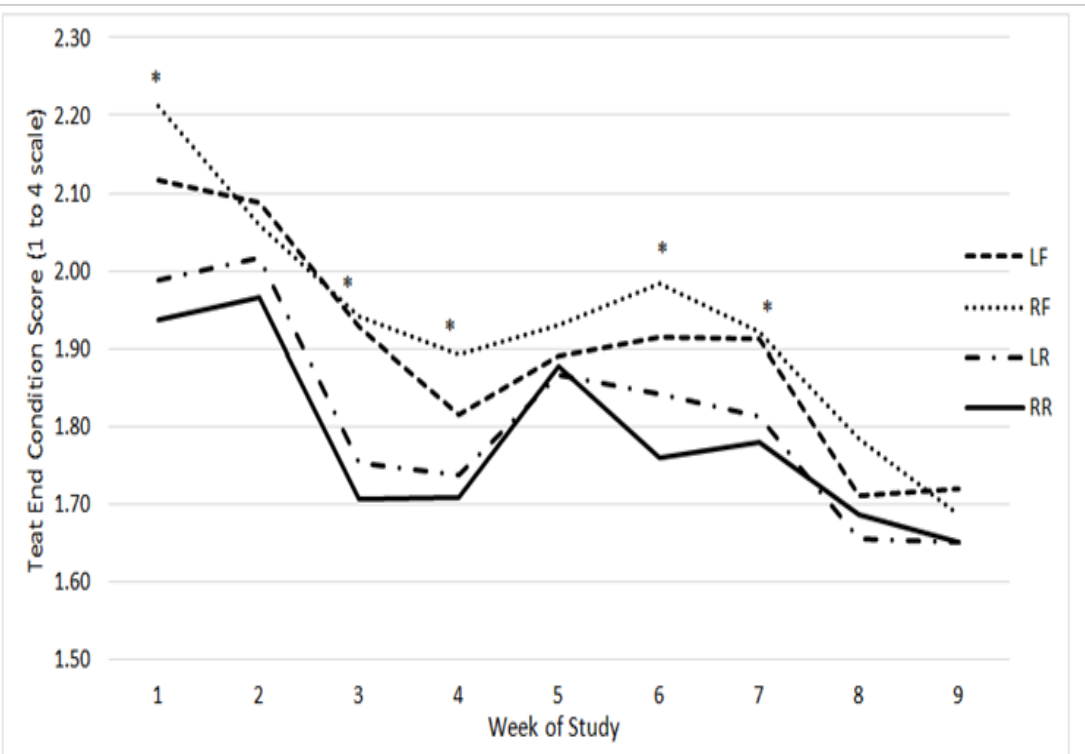

Figure 3 Least square means of a mixed linear model generated by the MIXED procedure of SAS Version 9.3 for teat end condition scores. Scores for the LF, RF, LR, and RR are distributed over time by the week of the study.

*indicates a week with a statistical difference $(\mathrm{P}<0.05)$. 
Figure 5 further illustrates a decrease in teat end condition scores in both the treatment side and control side. The LF, LR, and RF teats were scored significantly different and lower during week nine compared to week one, indicating teat condition improved over the course of the study. The RR teat remained around the same score throughout all 9 weeks of the study. As previously discussed, the difference in teat end condition and teat skin dryness scores overtime may be due to factors other than through the use of the treatment. Figure 6 displays similar information for teat dryness scores. However, the statistically significant increases in scores during weeks four through six, previously attributed to teat exfoliation, do not have a significant difference in scoring for the LR, the RF, and the RR teats. For the LF teat, week 3 is significantly different and greater than week five, which was the period that included the occurrence of teat exfoliation which temporarily resulted in greater dryness scores. Therefore, based on the data provided, the change in teat end condition and dryness scores during the study were not enough to declare this post-dip to be unusable. Further studies should be conducted with the same treatment to determine any effects with long-term use as well as testing in accordance with somatic cell count to better quantify its practical use in mastitis prevention.

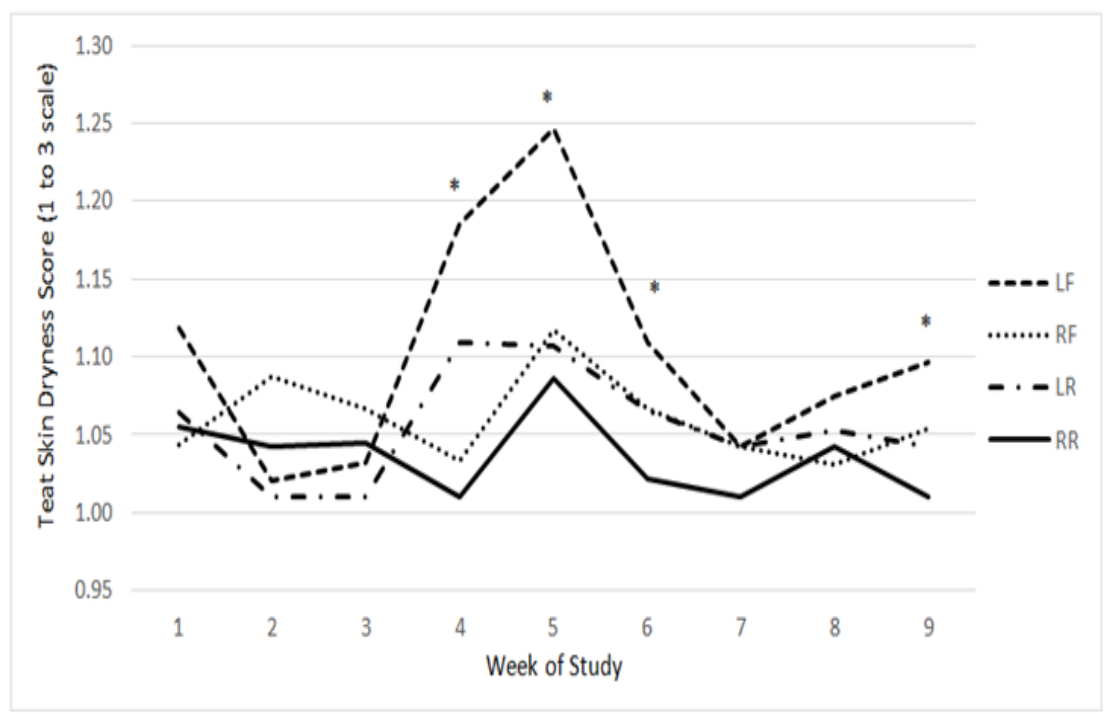

Figure 4 Least square means of a mixed linear model generated by the MIXED procedure of SASVersion 9.3 for teat skin dryness scores. Scores for the LF, RF, $L R$, and $R R$ are distributed over time by the week of the study.

*indicates a week with a statistical difference $(\mathrm{P}<0.05)$.

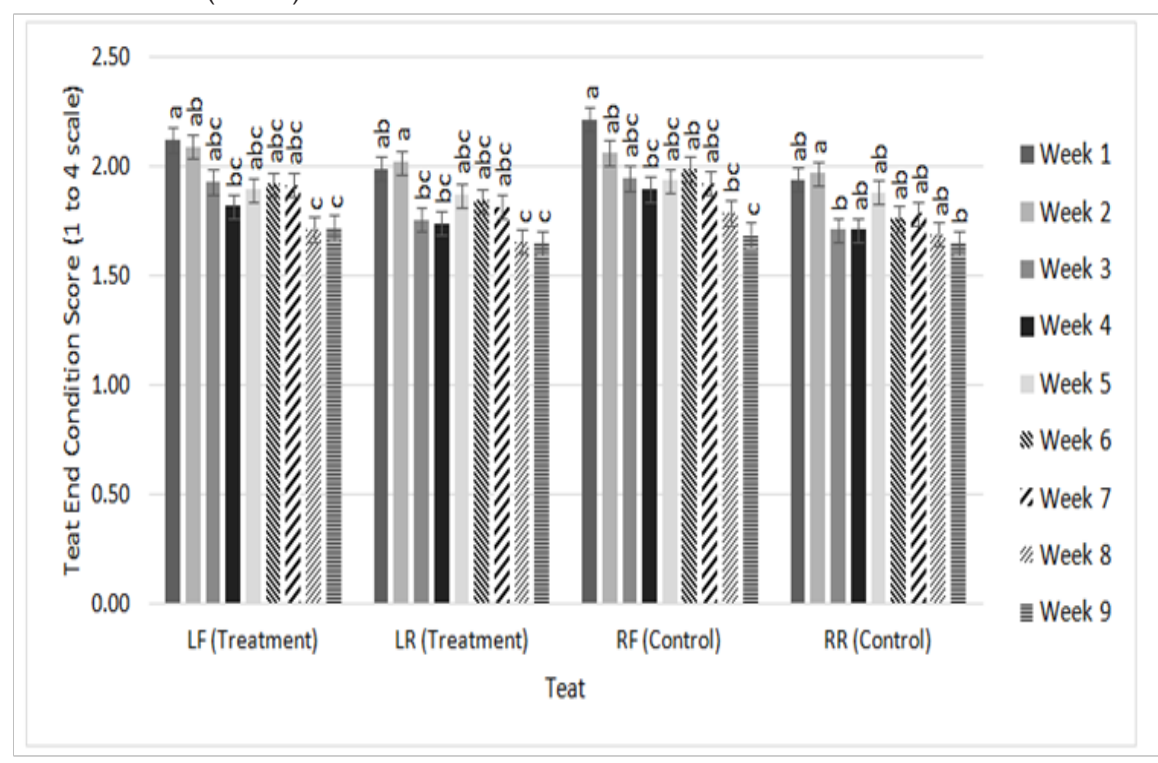

Figure 5 Weekly least square means of a mixed linear model generated by the MIXED procedure of SASVersion 9.3 for teat end condition scores. Scores for the LF, LR, LR, and RR are each distributed by all nine weeks.

'Bars differing in letters differ signfiicantly $(P<0.05)$. 


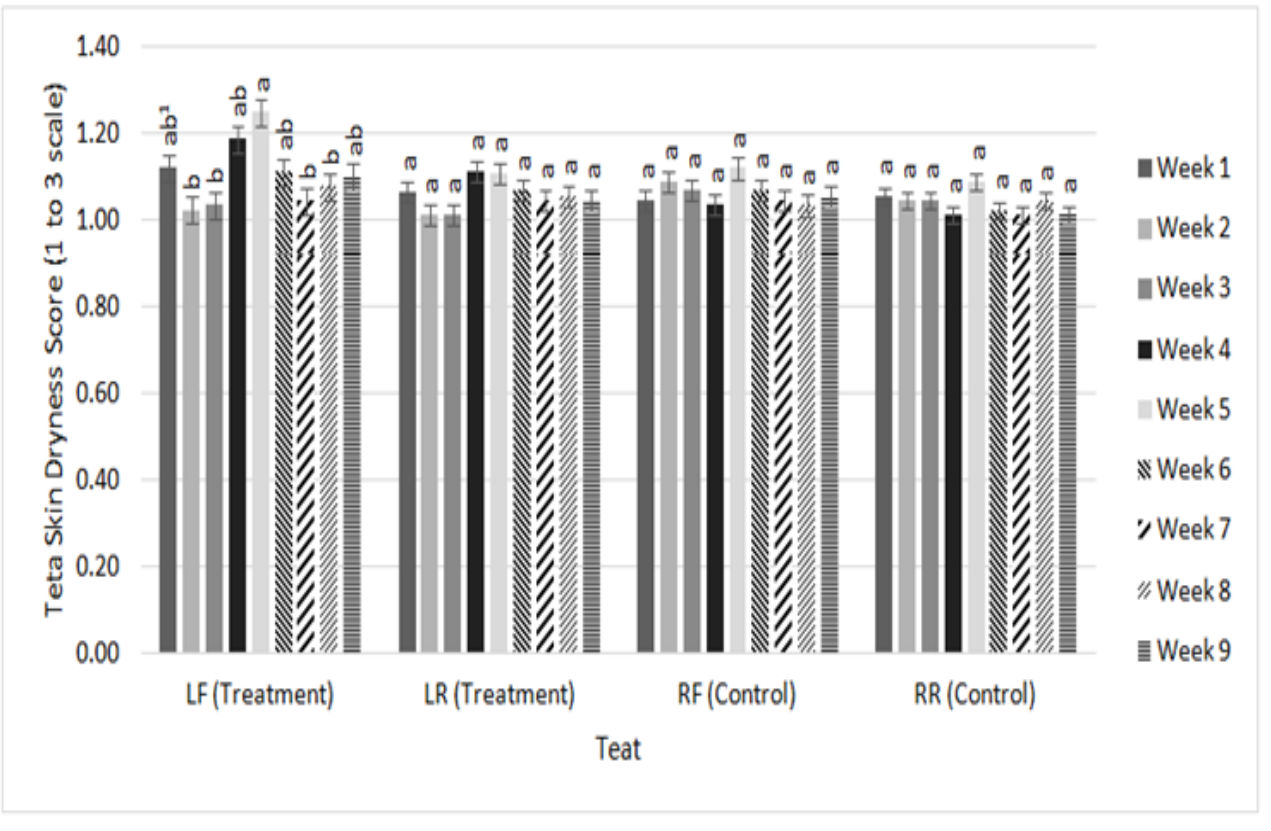

Figure 6 Weekly least square means of a mixed linear model generated by the MIXED procedure of SAS Version 9.3 for teat skin dryness scores. Scores for the LF, LR, LR, and RR are each distributed by all nine weeks.

'Bars differing in letters differ significantly $(P<0.05)$.

\section{Conclusion}

Teats treated with a post milking teat disinfectant containing the active ingredient, phenoxyethanol, resulted in minimal difference on teat health in comparison to a commonly used dip containing a $1 \%$ iodine solution. There were no changes in chapping or color throughout the duration of the study. Changes in teat end condition and dryness scores were attributed to various factors such as exfoliation, the transition of cows to a new barn, and the effect of differences in milk flow in front teats versus rear teats. Therefore, there is little evidence that would warrant this product to be ineffectual in comparison to an iodine dip and may serve as an alternative to iodine-based teat dips. Further tests should be conducted to determine any other long term usage effects.

\section{Acknowledgements}

The authors would like to thank Taylor Reiter for providing the tested product for this study. We would also like to thank Joey Clark, Amelia Fendley, and Brittany Core from the University of Kentucky for providing assistance throughout the study as well.

\section{Conflicts of interest}

The authors declare that there is no conflict of interest.

\section{References}

1. Zhao X, Lacasse P. Mammary tissue damage during bovine mastitis: causes and control. J Anim Sci. 2008;86(13 suppl):57-65.

2. Bhutto AL, Murray RD, Woldehiwet Z. Udder shape and teat-end lesions as potential risk factors for high somatic cell counts and intra-mammary infections in dairy cows. The Veterinary Journal. 2010;183(1):63-67.
3. Neijenhuis F, Mein G, Britt J, et al. Evaluation of bovine teat condition in commercial dairy herds: 4. Relationship between teat-end callosity or hyperkeratosis and mastitis. Proceedings of the 2nd International Symposium on Mastitis and Milk Quality, Canada; 2001.

4. Ohnstad I, Mein G, Baines J, et al. Addressing teat condition problems. Proceedings of the National Mastitis Council 46th Annual Meeting. USA; 2007.

5. Shathele M. Weather effect on bacterial mastitis in dairy cows. International Journal of Dairy Science. 2009;4(2):57-66.

6. Farnsworth RJ. Observations on teat lesions. Minnesota Dairy Health Conference, USA; 1995.

7. Morse D, DeLorenzo MA, Wilcox CJ, et al. Climatic Effects on Occurrence of Clinical Mastitis. J Dairy Sci. 1988;71(3):848-853.

8. Zeinhom MM, Aziz RLA, Mohammed AN, et al. Impact of Seasonal Conditions on Quality and Pathogens Content of Milk in Friesian Cows. Asian-Australasian J Ani Sci. 2016;29(8):1207.

9. Hillerton JE, Pankey J, Pankey P. Effect of over-milking on teat condition. J Dairy Res. 2002;69(01):81-84.

10. Dohmen W, Neijenhuis F, Hogeveen H. Relationship between udder health and hygiene on farms with an automatic milking system. J Dairy Sci. 2010;93(9):4019-4033.

11. Philpot WN. Control of Mastitis by Hygiene and Therapy. Journal of Dairy Science. 1979;62(1):168-176.

12. EPA. EPA Safer Choice: EPA. 2017.

13. NMC National Mastitis Council. Guidelines for Evaluating Teat Skin Condition. Verona, USA; 2007.

14. Tukey JW. Comparing Individual Means in the Analysis of Variance. Biometrics. 1949;5(2):99-114.

15. Johnson A, Rapnicki P, Farnsworth R, et al. Measuring effectiveness of teat preparation. 2003. 
16. Johansson I, Korkman N. Heritability of the udder proportions in dairy cows. Hereditas. 1952;38(2):131-151.

17. Rasmussen MD. Overmilking and teat condition. NMC Annual Meeting Proceedings. USA; 2004.
18. Ruud LE, Bøe KE, Østerås O. Associations of soft flooring materials in free stalls with milk yield, clinical mastitis, teat lesions, and removal of dairy cows. J Dairy Sci. 2010;93(4):1578-1586.

19. Timms LL. Evaluation of a Novel Chlorine Dioxide Teat Dip on Teat End and Teat Skin Health. Animal Industry Report. 2008;654(1):68. 